\title{
Working together or alone, near, or far: Social connections and communities of practice in in-person and remote physics laboratories
}

\author{
Drew J. Rosen $\odot^{*}$ \\ Stony Brook University, Institute for STEM Education, Stony Brook, New York 11794-5233, USA \\ Angela M. Kelly (1) \\ Stony Brook University, Department of Physics and Astronomy and Institute for STEM Education, \\ Stony Brook, New York 11794-5233, USA
}

(Received 17 May 2021; accepted 3 November 2021; published 12 January 2022)

\begin{abstract}
The proliferation of remote laboratory instruction increased substantially during the recent global pandemic. Many physics departments implemented this rapid transition without the previous experience, time, and deliberation to optimize learning experiences for students. The present quasi-experimental, nonequivalent group design study examined social connections and communities of practice in both inperson and remote undergraduate physics laboratories during the Fall 2020 academic semester. A social networking and communities of practice theoretical framework guided the study design and methodology. Study participants $(N=697)$ included in-person and remote undergraduate students in introductory physics laboratories at a research university in the Northeastern United States. A survey instrument was designed to measure students' perspectives relating to their social connectedness with peers and instructors as well as their physics laboratory self-efficacy. Survey factor analysis identified subdimensions related to student-student social learning perspectives, student-instructor social learning perspectives, and physics laboratory self-efficacy. Analysis of variance indicated remote students experienced weaker levels of engagement with instructors and peers than in-person students, and remote students who connected with one another experienced more social engagement than remote students who did not. Remote students who connected with one another reported having a lower physics laboratory self-efficacy than their in-person counterparts. Isolated remote students did not show a statistical difference in their physics laboratory selfefficacy from their remote-connecting nor their in-person counterparts. Correlations between factors were tested, with instructor interactions most closely related to self-efficacy formation. Results suggest that remote laboratories, which have proliferated extensively during the recent pandemic, may need formalized mechanisms and incentives to promote social interactions and foster communities of practice among peers. This is also the case for student-instructor interactions, which are often diminished in the online platform and may not be socially situated within the larger class community. Sources of self-efficacy, such as creating opportunities for vicarious learning, may also inform ways these changes can be made. Implications for policy and practice of remote physics laboratory instruction are discussed.
\end{abstract}

DOI: 10.1103/PhysRevPhysEducRes.18.010105

\section{INTRODUCTION}

Undergraduate physics laboratory experiences have been considered an essential component of physics learning [1,2]. As Richard Feynman once stated, "The principle of science, the definition almost, is the following: The test of all knowledge is experiment. Experiment is the sole judge of scientific "truth" " [3][p. 1-1]. Experiences with

\footnotetext{
*drew.rosen@stonybrook.edu

Published by the American Physical Society under the terms of the Creative Commons Attribution 4.0 International license. Further distribution of this work must maintain attribution to the author(s) and the published article's title, journal citation, and DOI.
}

experimental processes have been a common feature of undergraduate physics classes, with the intent of providing a means for students to strengthen conceptual learning, build analytical skills, and develop collaborative practices $[1,4]$. Students often construct physics knowledge by engaging in investigations based upon questions that require observations of phenomena and physical systems $[2,4]$. Although much research has focused on the value of social interactions and communities of practice for knowledge construction in the laboratory $[5,6]$, it is unclear whether these in-person interactions are universally advantageous for students to maximize self-efficacy and physics learning.

The COVID-19 global pandemic demonstrated the necessity for universities to have remote learning 
capabilities. Pedagogical practices during this time were driven by a need for a rapid transition, often at the expense of intentional, refined instructional design [7]. Some challenges with this transition were compounded because many faculty were lacking in experience with remote learning, which requires careful consideration of student experiences when making decisions regarding implementation $[8,9]$. Remote laboratories require consistency in information flow between instructors and students, with newly devised modes of interaction to substitute for inperson communications [10].

Physics laboratory instruction has faced unique challenges posed by the pandemic. Labs are typically conducted in person with students in close proximity to their peers while handling the same equipment, something not feasible during a global pandemic. A significant challenge posed by emergency remote teaching was maintaining academic and experiential consistency with in-person laboratory classes [11]. One such aspect of laboratory practices is collaboration, often considered a central part of scientific processes [12], with collaborative teams producing more high impact research than individuals working alone [13]. This notion was challenged during the transition to emergency remote teaching, when students went from mostly performing laboratory work in groups $(5.5 \%$ doing individual work only) to mostly doing laboratory work on their own (55.6\% doing individual work only) [11].

The emergency transition to remote classes had some negative consequences for students' learning experiences. A recent report indicated $89 \%$ of students in remote physics reported a reduced level of interaction, with the majority (72\%) stating this had a negative impact on their physics comprehension. Furthermore, most students (77\%) needed to devote more time than usual to their physics courses while they $(81 \%)$ simultaneously experienced decreased motivation in completing course requirements $[8,9]$.

The recent reliance on remote instruction in physics undergraduate coursework requires closer examination of student outcomes to improve future iterations of remote learning. The relatively short-term experiences of these students conducting remote laboratory work may have important consequences for their communication with peers and instructors, as well as affective domains including self-efficacy in completing laboratory tasks. These considerations may have long-term implications for physics identity formation, performance, persistence, and career choice $[14,15]$. The present study explored the perceptions of social learning and laboratory self-efficacy of physics undergraduates who participated in asynchronous remote or in-person laboratory work during the pandemic in Fall 2020.

\section{A. Social learning in physics}

Social interactions often facilitate the co-construction of knowledge [16]. Social learning may involve activities such as sharing information, troubleshooting challenges, and learning from the experiences of others [17]. Individual and collective learning may be mutually reinforced as instructors guide students toward achieving educational goals [17]. Research has suggested that students tend to view social interaction as a positive aspect of physics laboratory classes [6].

The social nature of learning involves student-student, student-instructor, and student-content interactions [18]. Student learning is often mediated by interactions with the physics instructor, who engages students, questions their knowledge, and provides support for managing complex tasks [19]. When students and instructors do not engage in direct communication, students may benefit from autonomy while also feeling burdened by limited feedback and assuming a greater share of responsibility for overcoming conceptual challenges [18].

Although social interaction has been identified as a key component of learning subjects such as science [20,21], this notion has been challenged by research that suggested collaboration alone does not always result in positive cognitive outcomes [22]. For example, physics knowledge acquisition that occurs individually through problem-based learning has been shown to be more effective than engaging in social collaboration [23]. This has important implications considering the recent proliferation of remote learning, where students may need to develop conceptual understandings without meaningful interactions with peers or instructors.

\section{B. Nature of in-person vs remote laboratories}

In-person laboratory structures have some key structural differences with asynchronous remote labs. During inperson laboratories, students work in small groups and physically manipulate physical laboratory equipment under the guidance of instructors. Students in remote laboratories experience physical and psychological separation from peers, instructors, and in many cases, typical laboratory equipment $[18,24]$. However, unlike virtual labs, which are based upon simulations, remote labs require physical devices and space to perform experiments [25]. The learning environment may include technology-mediated interfaces, select pedagogical strategies, and consistent interactions with the same instructor [26,27].

While some would argue that remote laboratory teaching should be a temporary measure citing the difficulties of meeting critical learning goals [11], remote instruction presents positive benefits related to cost and accessibility. Remote physics experiments provide a solution for schools that face increasing demand for laboratories that may not expand physical space or equipment due to cost [28]. These experiments create opportunities for students such as those with disabilities who may otherwise not be able to access a laboratory or use typical equipment, as well as nontraditional students who are employed or care for family 
members [28-30]. Autonomous, flexible, and self-paced remote laboratories may be especially beneficial for nontraditional students since the materials may be accessed at any time [31].

With all the benefits of remote laboratories come potential pitfalls. Students will need internet access to retrieve course materials and communicate with others. There are additional financial costs associated with a remote laboratory course including laboratory kits for athome use [32]. This could become a barrier for nontraditional students who may benefit from the flexibility of a remote laboratory course. Students with lower selfefficacy associated with using novel technologies, like those used in a remote laboratory class, may be less motivated to engage with laboratory equipment they have to troubleshoot on their own. They may also be hesitant to utilize unfamiliar online communication platforms, which could influence course satisfaction and performance [33].

While remote laboratories have been examined in prior research [7,10,11,24,25,34,35], often the focus of such studies has been on the novelty of the technology or learning outcomes $[24,34,35]$. Results have been inconclusive regarding the potential of remote laboratories to mirror in-person classroom environments, since these experiences are fundamentally different from in-person laboratories $[11,27,28]$. Research comparing social interactions in in-person and remote laboratories has been lacking [24] and is needed to understand the role of technology in how students are and should be collaborating [25]. In an effort to explore underlying student behaviors that may influence social engagement, the present study examines social interactions and self-efficacy in both inperson and remote physics laboratories.

\section{THEORETICAL FRAMEWORK}

The theoretical framework for the present study was derived from the role of social networks and communities of practice in value creation, as proposed by Wenger et al. [17]. Their framework stipulated that the social activities of networks and communities may be linked to positive affective outcomes such as self-efficacy (the belief in one's ability to succeed in doing specific tasks [36]). They suggested that the explicit facilitation and support of networks and communities may create value in the form of knowledge capital, collaborative reflection, and confidence in one's ability to engage in shared practices [17].

Social communities are often formed by the accumulation of personal connections who share information and facilitate knowledge capital [17]. In the case of the physics laboratory, social connections provide a mechanism to solve problems collaboratively. The participants within an academic community are often committed to learning the skills and knowledge required to perform well in the course while advancing their long-term academic goals [37], although level of commitment may vary.
While students taking an in-person laboratory class may leverage their physical proximity to connect socially with their classmates, remote learners, especially those in an asynchronous environment, may not have that immediate opportunity [24,38]. They have to instead rely upon preexisting networks to connect with their classmates [37,39], or remote learners may not have the opportunity to connect at all. Being part of a college campus provides access and opportunities for students to be a part of many diverse social networks including friends, dormmates, classmates, clubs, sports teams, or other social groups $[38,40,41]$. Individual communication styles or even a willingness to communicate may influence how remote learners make social connections [37].

Communities of practice may evolve when members form a shared identity and collective intention around a particular set of challenges [17]. Communities of practice are "groups of people who share a concern, a set of problems, or a passion about a topic, and who deepen their knowledge and expertise by interacting on an ongoing basis" [42] (p. 4). Communities of practice have three key elements shared among members: domain, community, and practice. A domain is the body of knowledge that defines the issues or problems members commonly face, creating shared experiences and a common identity [42]. The community is the "social fabric of learning" that "fosters interactions based on mutual respect and trust" [42] (p. 28). The practice is the set of socially defined tools, information, approaches, and standards that are shared among members creating "a sort of mini-culture that binds the community together" [42] (p. 39).

In a classroom laboratory community of practice, students are socially engaged with one another and their instructor in a space (whether it be physical or virtual) that provides opportunities for mutual engagement in shared practices working towards common goals [43]. Instructors support students by acting as experts, or central participants of the community, guiding less experienced new members, or peripheral participants of the community, towards becoming more experienced members [44,45]. This becomes advantageous in an in-person laboratory classroom where the instructor has a limited amount of time; more experienced students can become a source of knowledge and expertise and help facilitate learning. Thus, students may rely on the distributed experience of their fellow classmates which further facilitates collaboration [43].

In the physics laboratory, students share common goals and often need opportunities to engage with classmates who face similar situations and challenges [42]. Physics laboratory instructors may facilitate communities and networks to promote desired student outcomes [16], which may include improved scientific practices, cognitive learning, and academic agency [46,47]. Proactive, mediated community formation may increase communication among 
students, peers, and expert instructors in zones of proximal development $[44,48]$. This allows greater access to expert instructors who may provide more feedback to strengthen students' metacognition, confidence, and sense of their performance in comparison to peers [44].

Social connections create value for participants in communities of practice. Socialization has often facilitated a sense of belonging in a community, which is further incentivized by shared values [17]. According to Irving et al. [46], physics curriculum design based in the communities of practice framework has several advantages, including physics confidence, identity development, sense of belonging, and the encouragement of risk taking. The physics laboratory experience provides a space for students to engage in scientific tasks; in doing so, they may experience agency and physics identity formation while building self-efficacy [46]. Self-efficacy may also be built through recognition by instructors or peers [49]. Instructors may facilitate connections to both physics content and the physics learning communities through both implicit and explicit recognition, and by supporting structured autonomy and providing formative feedback [50]. Since student-student and student-instructor interactions frequently diminish in remote laboratories [28], interventions may be needed to facilitate connections and communities to achieve the same positive outcomes. This is important since affective domains such as self-efficacy have been shown to predict academic persistence and career choice [51].

\section{A. Research questions}

Research has established the importance of laboratory work in physics learning [1,2], and the traditional in-person structure of laboratory learning has been redefined during the recent global pandemic. Research has indicated the value of social learning in promoting positive academic and affective outcomes $[6,17,20,21,52]$, however, research is needed on how social connections and communities of practices may influence student outcomes in remote laboratory environments [24]. Based on a social connections and communities of practice framework that was integrated in a quasiexperimental design, the present study examined social community formation through the following research questions:

(i) To what extent do students in remote laboratory classes generate social connections with their classmates and instructors?

(ii) How does the laboratory environment relate to physics laboratory self-efficacy, and is there a relationship between students' self-efficacy and their social learning perspectives?

\section{DESIGN}

This study employed a quasiexperimental, nonequivalent group design [53]. A survey instrument was designed to measure students' student-student and student-instructor social learning perspectives as well as students' physics laboratory self-efficacy. Factor analysis, comparisons of means, and correlations (including partial correlations) were performed to identify subdimensions of the instrument, assess their relationship to each other, and measure group differences in each dimension.

\section{A. Context}

This survey was conducted at a large, public university in the Northeastern U.S. in the Fall 2020 semester. This university served nearly 18000 undergraduate students. During a typical year (2019), students were evenly divided between commuter (approximately 8500) and on-campus residents (approximately 9400). Because of the ongoing global pandemic during the Fall 2020 semester, 14000 students were classified as commuters and approximately 4000 were classified as on-campus residents. In-person undergraduate physics laboratories for physical science and engineering majors enrolled 614 students and the remote, asynchronous laboratories enrolled 603 students. Of this population, $62 \%$ of the in-person $(N=381)$ and $52 \%$ of the remote students $(N=316)$ participated in the study, for a total sample $N=697$ students. The laboratory course was the first of a two-semester, calculus-based sequence. The laboratory was a required component of the introductory course, constituting $25 \%$ of the final grade.

\section{B. Laboratory structures}

Students in both the in-person and remote laboratories were required to complete ten experiments based on topics covered in the corresponding mechanics lecture course. They were evaluated based on written laboratory reports with students submitting individual reports each week.

Each in-person laboratory section enrolled approximately 12 students working in pairs in a laboratory room; this was half the typical enrollment due to social distancing requirements. Students worked at laboratory tables in close proximity to one another with one instructor, typically a graduate teaching assistant, giving an introductory lecture and walking around the room while students completed experiments. Laboratory partners were separated by a clear divider with one student handling the equipment and one student handling the computer. Students could communicate with their partners, other groups, and teaching assistants.

The remote laboratories were typically completed by students either in their dormitories on campus or in their homes off campus. The experiments were completed asynchronously and usually alone. Students would utilize the iOLab device and associated software to take their measurements [54]. In addition to written background and procedures, students had access to videos of the course instructor reviewing the background physics and demonstrating the experimental apparatus. Students could ask 
questions of their assigned teaching assistant through email. This was generally the only way students communicated with them. Instructors did try to facilitate communication between students by inviting some students to participate through a Slack channel, an online discussion board. Participation was low and ultimately students who participated in the designated channel were removed from this study. The factor analysis and findings of this study were not altered when removing these students.

The ten laboratory experiments and learning objectives were equivalent in the in-person and remote semesterlong classes. Topics focused on kinematics, mechanics, momentum, energy conservation, and wave motion; students had similar expectations with regard to written reports. A more detailed account describing the implementation and nature of these experiments can be found in Ref. [52]. The main difference between classes was individual vs group task completion, which often involve different levels of cognitive challenge. The task complexity of each experiment may be considered in terms of time for completion and efficiency, as demonstrated by Almaatouq et al. [55]. Although in-person groups had a time limit on task completion, their work was more theoretically efficient due to group interaction. Conversely, remote students worked alone yet had more time to maximize data accuracy and precision since they worked at their own pace. Consequently, duration and efficiency for both groups were estimated to be equivalent when taken together, although group interaction likely varied among students attending in-person laboratories.

\section{Survey design and administration}

The survey was derived from literature on students' experiences in collaborative settings, classroom community, and self-efficacy [15,56-64]. Prior instruments were reviewed to select items consistent with the theoretical framework and research questions; some items were modified to fit within the context of the physics laboratory course. Three physics education experts provided content validity at the item level in terms of relevance and congruence with the laboratory structure and learning objectives. A pilot survey was administered with 42 items: $n=207$ students in an algebra-based version of the same in-person or remote physics laboratory course and $n=16$ students in a calculus-based remote course. In order to achieve a minimum reliability of 0.70 for each factor, several items were reconsidered. Five items relating to sense of belonging were eliminated because the source of sense of belonging was ambiguous (interactions with instructors, peers, or something else entirely). Three items relating to interactions were removed because they loaded equivalently onto multiple factors, thus their relationship to latent constructs was unclear. Two items were removed because they did not translate well into a remote laboratory setting.
The final survey items are listed in Table I, with the associated source indicated. Some survey items were modified to align with this study. Items with an [R] were reverse coded. Students' rated responses $(N=697)$ on a five-point Likert scale $(5=$ strongly agree, $4=$ somewhat agree, $3=$ neither agree nor disagree, $2=$ somewhat disagree, $1=$ strongly disagree). An attention check item (asking students to respond to a question in a particular way) was used to detect inattentive or careless students who were then removed from the sample [65]. Eleven missing responses were deleted listwise. Students were also asked whether and/or how they were communicating with other students in their laboratory classes. They could choose more than one method.

Because this study examined students' experiences working in their respective laboratory classes, students were surveyed two-thirds of the way into the semester. They were incentivized to participate in this survey, with every student in the class earning extra credit if the response rate was least $50 \%$.

\section{RESULTS}

The results from the present study are presented here, including survey reliability, descriptive statistics, factor analysis and analysis of variance (ANOVA) solutions, and the correlations between factors relating to students' social learning perspectives and their self-efficacy. For the purposes of the ANOVA and correlations, students were divided into three mutually exclusive groups. Given that the vast majority of remote students did in fact connect with one another, those students who did connect (remote connectors, $n=276$ ) were split from those who remained isolated (remote isolated, $n=40$ ), as these represented two distinct kinds of social experiences for students, to ultimately compare these groups to in-person students $(n=381)$.

\section{A. Students' modes of communication}

Although frequent communication with peers was presumed for the in-person students, who worked side by side with laboratory partners in close proximity to other groups, it was unclear whether and/or how remote students were communicating with each other. The survey included a question on the types of communication in which these students may have engaged with peers. Response frequencies for this question are found in Fig. 1.

Forty remote students reported they did not connect with other students in their laboratory class (remote isolated), and 283 remote students reported that they did connect with other students (remote connectors). Students connecting with one another likely involved communication through preexisting social connections. Most often, these included GroupMe and texting or social media applications such as 
TABLE I. Survey of undergraduate physics social learning perspectives and physics laboratory self-efficacy. Absolute values of factor loadings above 0.30 are bolded.

\begin{tabular}{|c|c|c|c|}
\hline & Factor 1 & Factor 2 & Factor 3 \\
\hline \multicolumn{4}{|l|}{ Factor 1: Student-student social learning perspectives $(\alpha=0.89)$} \\
\hline 1. I am able to depend on other students for help with my physics lab. [56] & 0.60 & 0.07 & 0.04 \\
\hline $\begin{array}{l}\text { 2. When I have difficulty solving a physics laboratory problem, I like to discuss } \\
\text { the problem with a peer. [57] }\end{array}$ & 0.57 & 0.19 & 0.05 \\
\hline 3. Working with other students encourages and motivates me in this class. [15] & 0.51 & 0.09 & 0.02 \\
\hline 4. I have little chance to get to know other students in my laboratory class. [R] [56] & 0.52 & 0.12 & 0.05 \\
\hline 5. I feel that students in this course care about each other. [58] & 0.54 & 0.12 & 0.02 \\
\hline 6. I feel connected to others in this course. [58] & 0.70 & 0.07 & 0.03 \\
\hline 7. I feel that I can rely on others in this course. [58] & 0.79 & 0.04 & 0.04 \\
\hline 8. I feel that members of this course depend on me. [58] & 0.46 & 0.07 & 0.18 \\
\hline 9. I feel isolated in this course. [R] [58] & 0.57 & 0.27 & 0.03 \\
\hline 10. Members of my laboratory class help me. [56] & 0.80 & 0.03 & 0.10 \\
\hline 11. I find it easy to communicate with other students in my laboratory class. [58] & 0.75 & 0.06 & 0.00 \\
\hline 12. I feel confident that others will support me. [58] & 0.69 & 0.12 & 0.07 \\
\hline \multicolumn{4}{|l|}{ Factor 2: Student-Instructor social learning perspectives $(\alpha=0.85)$} \\
\hline 13. I feel that it is hard to get help when I have a question. [R] [58] & 0.22 & 0.55 & 0.09 \\
\hline 14. I feel that I receive timely feedback. [58] & 0.03 & 0.66 & 0.02 \\
\hline 15. I feel that my educational needs are not being met. [R] [58] & 0.06 & 0.53 & 0.10 \\
\hline 16. My laboratory instructor(s) really care about my success in the laboratory course. [59] & 0.09 & 0.68 & 0.02 \\
\hline 17. I feel as though my laboratory instructor(s) treat me the same as other students. [59] & 0.08 & 0.50 & 0.01 \\
\hline 18. My instructors provide lots of written feedback on the assignments I turn in. [59] & 0.10 & 0.70 & 0.09 \\
\hline 19. I feel accepted as a capable student by my instructor(s). [59] & 0.01 & 0.72 & 0.10 \\
\hline $\begin{array}{l}\text { 20. My laboratory teaching assistant(s) makes me feel like I could continue } \\
\text { in science if I wanted to. [60] }\end{array}$ & 0.00 & 0.64 & 0.11 \\
\hline \multicolumn{4}{|l|}{ Factor 3: Physics laboratory self-efficacy $(\alpha=0.88)$} \\
\hline 21. I feel I could critique a laboratory report written by another student. [61] & 0.05 & 0.04 & 0.64 \\
\hline $\begin{array}{l}\text { 22. I am confident that I could read the procedures for an experiment and conduct the } \\
\text { experiment on my own. [61] }\end{array}$ & 0.09 & 0.01 & 0.56 \\
\hline $\begin{array}{l}\text { 23. I am confident that I could use a scientific approach to solve an everyday } \\
\text { problem outside of a classroom setting. [61] }\end{array}$ & 0.03 & 0.02 & 0.60 \\
\hline $\begin{array}{l}\text { 24. I am confident that I could analyze a set of data to answer a scientific question } \\
\text { (i.e., look at the relationships between variables). [59] }\end{array}$ & 0.01 & 0.01 & 0.60 \\
\hline 25. I am confident that I could tutor another student on how to write a lab report. [61] & 0.01 & 0.14 & 0.70 \\
\hline $\begin{array}{l}\text { 26. I feel comfortable expressing my opinions when others in my laboratory } \\
\text { class disagree with me. [62] }\end{array}$ & 0.06 & 0.03 & 0.56 \\
\hline 27. I feel I am capable of defending my physics ideas to my peers in my laboratory class. [62] & 0.12 & 0.00 & 0.71 \\
\hline 28. Doing laboratory experiments and write-ups comes easy to me. [63] & 0.01 & 0.14 & 0.60 \\
\hline 29. I feel I am capable of helping my classmates with physics in the laboratory. [63] & 0.12 & 0.00 & 0.71 \\
\hline 30. I know how to explain what I do in the laboratory effectively. [63] & 0.03 & 0.01 & 0.70 \\
\hline 31. I feel I can overcome any problems I encounter in an experiment. [64] & 0.09 & 0.05 & 0.49 \\
\hline 32. Before doing an experiment, I clearly understand the theory behind it. [60] & 0.03 & 0.06 & 0.54 \\
\hline
\end{tabular}

Snapchat and Facebook. Others used video chat, email, and Discord.

\section{B. Survey factor analysis}

After the survey was administered to all students in the sample, the model presented in the theoretical framework was tested. A principal axis factor analysis was conducted on the 32 items in the survey. Sampling adequacy was demonstrated through the Kaiser-Meyer-Olkin measure of 0.92 (above 0.90 being "marvelous" as defined by Kaiser [66]). By examining possible factors with eigenvalues greater than one and the inflection point of the resulting scree plot, a four-factor solution was first explored. Because no items loaded above 0.30 onto one of the factors, a three-factor solution was identified, accounting for $43 \%$ of the total variance. No items shifted factors as a result of this change. The survey had acceptable overall reliability (Cronbach's $\alpha=0.91$ ).

A direct oblimin rotation $(\delta=0)$ was used for the analysis. Table I indicates the survey items and respective loadings. No items had cross loadings above 0.30. The identified factors represented (1) student-student social learning perspectives, (2) student-instructor social learning perspectives, and (3) physics laboratory self-efficacy. 


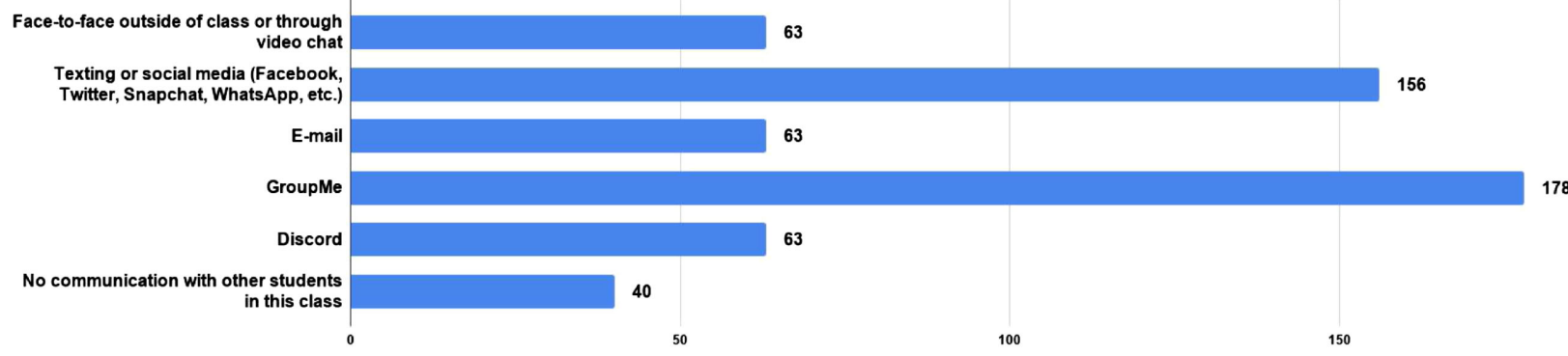

FIG. 1. Communication types and frequencies for remote students enrolled in undergraduate physics laboratories.

Factor 1, identified as "student-student social learning perspectives," included 12 items $(\alpha=0.89)$. Questions from this factor related to a student's sense of being part of a community of practice with their fellow classmates. These items collectively relate to a student's value of peer interactions for learning physics, fostering motivation, experiencing connectedness, growing confidence, and diminishing isolation. These positive outcomes may have originated in their collaborative practices with their classmates, social connections, or their sense of belonging from their relationships with peers. Although researchers have identified student-student socialization and collaboration as means to strengthen affective and cognitive outcomes $[6,17,20,21,52,67-69]$, research has suggested that the authenticity of physics learning tasks has a greater impact on student learning [23].

Factor 2, "student-instructor social learning perspectives," was represented by 8 items $(\alpha=0.85)$. Questions related to a student's sense of being part of a community of practice with their instructors. This may have come about through social interactions with instructors that involved feedback related to procedural clarifications, troubleshooting the apparatus, problem solving, help with calculations, or other questions related to completing the experiments and written report. Research has shown that student learning is enhanced by instructors who promote two-way information flow, provide timely and detailed feedback, and communicate confidence that students may think for themselves [19].

Factor 3, defined as "physics laboratory self-efficacy," was represented by 12 items $(\alpha=0.88)$. Questions related to students' confidence in their capabilities to complete specific tasks in their physics laboratory courses. The shortterm, task-specific nature of the self-efficacy items reflects students' confidence in their ability to apply physics concepts in the laboratory, defend their ideas, perform experiments, analyze data, communicate results, transfer process skills to real world contexts, troubleshoot, help their peers, and evaluate the work of others. Physics self-efficacy has been shown to be positively correlated with interest, performance, persistence, and career choice $[15,46]$. Physics self-efficacy may be strengthened or weakened by social interactions, since students may formulate task confidence by verbal persuasion experiences [70].

\section{Analysis of variance}

Subsequent inferential analyses compared remote-connector $(n=276)$ and remote-isolated $(n=40)$ student groups with students taking the in-person version of the course $(n=381)$. Remote students were grouped based on whether they were connecting with other students, regardless of method or frequency.

A one-way analysis of variance was used to compare the composite scores of the items in each factor for in-person, remote-connector, and remote-isolated students. The null hypothesis was that there was no difference between groups for a particular construct. Post hoc pairwise comparisons (Tukey or Games-Howell) were used to determine specific between-group differences. Overall effect sizes were defined based on recommendations by Cohen $(0.1,0.3$, and 0.5 corresponding to small, medium, and large effect sizes, respectively) [71]. These inferential and descriptive results are summarized in Table II.

For factor 1 (student-student social learning perspectives), there were significant differences among the three groups $[F(2,694)=101.13, p<0.001]$ with a large effect size $(r=0.48)$. Post hoc Tukey's HSD indicated more positive responses from in-person students when compared to both remote-connectors $(p<0.001)$ and remote-isolated students $(p<0.001)$, as well as more positive responses from remote connectors when compared to remote isolated $(p<0.001)$.

For factor 2 (student-instructor social learning perspectives), there were significant differences $[F(2,113.54)=$ $130.54, p<0.001$ ] with a medium to large effect size $(r=0.40)$. Because Levene's $\mathrm{F}$ test indicated unequal variances $[F(2,694)=4.57, p=0.011]$, Welch's $F$ test was used rather than the classic ANOVA [72]. A post hoc Games-Howell test indicated more positive responses from in-person students when compared to both remote-connector $(p<0.001)$ and remote-isolated $(p<0.001)$ students, and no significant difference between the remote groups $(p=0.819)$.

For factor 3 (physics laboratory self-efficacy), there were significant differences $[F(2,694)=5.07, p=0.007]$ with a small effect size $(r=0.12)$. Post hoc Tukey's HSD indicated more positive responses from in-person students when compared to remote connectors $(p=0.005)$, and no 
TABLE II. Inferential and descriptive statistics of factor differences among in-person, remote-connector, and remote-isolated students $(N=697)$.

\begin{tabular}{|c|c|c|c|c|c|c|c|c|c|}
\hline \multirow[b]{2}{*}{ Factor } & \multirow[b]{2}{*}{ Group } & \multirow[b]{2}{*}{$N$} & \multirow[b]{2}{*}{ Mean } & \multirow[b]{2}{*}{$\mathrm{SD}$} & \multirow[b]{2}{*}{$F$} & \multirow[b]{2}{*}{$p$} & \multirow[b]{2}{*}{ Effect size $(r)$} & \multicolumn{2}{|c|}{$95 \%$ Confidence interval } \\
\hline & & & & & & & & Lower bound & Upper bound \\
\hline \multirow{3}{*}{$\begin{array}{l}\text { 1. Student-student social } \\
\text { learning perspectives }\end{array}$} & In person & 381 & 41.34 & 8.00 & \multirow{3}{*}{101.13} & \multirow{3}{*}{$<0.001$} & \multirow{3}{*}{0.48} & 40.54 & 42.15 \\
\hline & Remote-Connector & 276 & 35.79 & 8.55 & & & & 34.78 & 36.81 \\
\hline & Remote-Isolated & 40 & 23.98 & 6.65 & & & & 21.85 & 26.10 \\
\hline \multirow{3}{*}{$\begin{array}{l}\text { 2. Student-instructor } \\
\text { social learning perspectives }\end{array}$} & In person & 381 & 31.75 & 5.31 & \multirow{3}{*}{130.54} & \multirow{3}{*}{$<0.001$} & \multirow{3}{*}{0.40} & 31.21 & 32.28 \\
\hline & Remote-Connector & 276 & 26.68 & 6.31 & & & & 25.93 & 27.43 \\
\hline & Remote-Isolated & 40 & 27.25 & 5.49 & & & & 25.49 & 29.01 \\
\hline \multirow{3}{*}{$\begin{array}{l}\text { 3. Physics laboratory } \\
\text { self-efficacy }\end{array}$} & In person & 381 & 43.36 & 7.65 & \multirow{3}{*}{5.07} & \multirow{3}{*}{0.007} & \multirow{3}{*}{0.12} & 42.59 & 44.14 \\
\hline & Remote-Connector & 276 & 41.39 & 8.41 & & & & 40.39 & 42.39 \\
\hline & Remote-Isolated & 40 & 41.70 & 8.48 & & & & 38.99 & 44.41 \\
\hline
\end{tabular}

differences between each of the remote groups $(p=0.972)$ or in-person and remote-isolated students $(p=0.424)$.

\section{Correlations between factors}

Measuring the relationship between social learning perspectives and self-efficacy may serve to identify links among social connections, communities of practice, and self-efficacy as proposed in the theoretical framework; potential links may guide instructors on designating resources to improve student learning [17]. In order to assess potential relationships among the three factors, Pearson's correlations were measured, with partial correlations done to control for shared variance among all three factors. Correlations were calculated for each group (inperson, remote-connector, remote-isolated) separately so the strength of each factor relationship could be compared. The percentage of shared variance between each factor as well as the shared variance among all three factors for each of the groups is shown in Fig. 2.

\section{In-person students}

Physics laboratory self-efficacy was positively correlated with student-student social learning perspectives $[r(380)=0.28, p<0.001]$. When controlling for student-instructor social learning perspectives, they were still positively correlated $[r(379)=0.17, p=0.001]$.

Physics laboratory self-efficacy was positively correlated with student-instructor social learning perspectives $[r(380)=0.34, p<0.001]$. When controlling for student-student social learning perspectives, they were still positively correlated $[r(379)=0.27, p<0.001]$.

Student-student social learning perspectives were positively correlated with student-instructor social learning perspectives $[(380)=0.39, p<0.001]$. When controlling for physics laboratory self-efficacy, they were still positively correlated $[r(379)=0.33, p<0.001]$.

For students enrolled in onsite physics labs, self-efficacy was related to both their interactions with their classmates and their interactions with their instructors. Thus, both are a potential source of self-efficacy. The large shared variance between the factors relating to student-student and studentinstructor social learning perspectives suggests a strong social classroom environment.

\section{Remote-connector students}

For remote-connector students, physics laboratory selfefficacy was positively correlated with student-student social learning perspectives $[r(278)=0.18, p=0.002]$. When controlling for student-instructor social learning perspectives, they were not significantly correlated $(p=0.187)$.

Physics laboratory self-efficacy was positively correlated with student-instructor social learning perspectives $[r(380)=0.43, p<0.001]$. When controlling for studentstudent social learning perspectives, they were still positively correlated $[r(277)=0.41, p<0.001]$.

Student-student social learning perspectives were positively correlated with student-instructor social learning perspectives $[r(278)=0.26, p<0.001]$. When controlling for physics laboratory self-efficacy, they were still positively correlated $[r(277)=0.20, p=0.001]$.

Self-efficacy was not significantly related to students' interactions with their classmates even when they connected with others in a remote laboratory environment, only their interactions with their instructors related to their selfefficacy. The shared variance between the factors relating to student-student and student-instructor social learning perspectives suggests a social classroom environment, though the correlation is a weaker one when compared to the inperson laboratory.

\section{Remote-isolated students}

For remote-isolated students, physics laboratory selfefficacy was not significantly correlated with student-student social learning perspectives $(p=0.132)$. Physics laboratory self-efficacy was positively correlated with studentinstructor social learning perspectives $[r(38)=0.65$, $p<0.001]$. Student-student social learning perspectives 


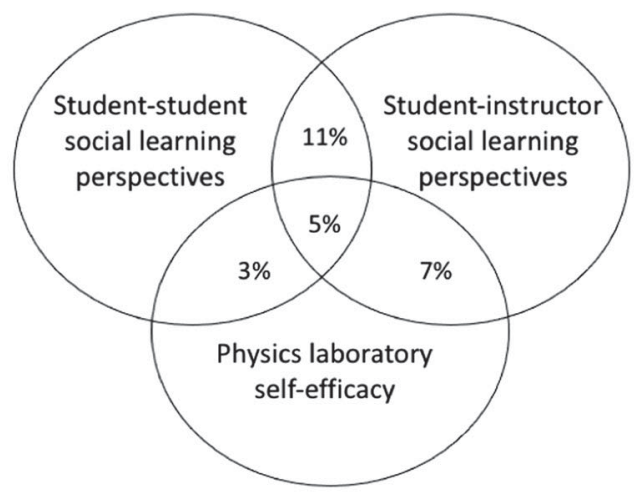

(a) In-person students

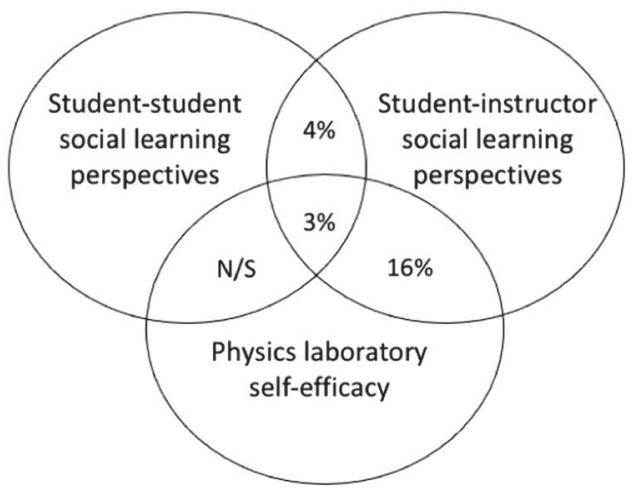

(b) Remote-connector students

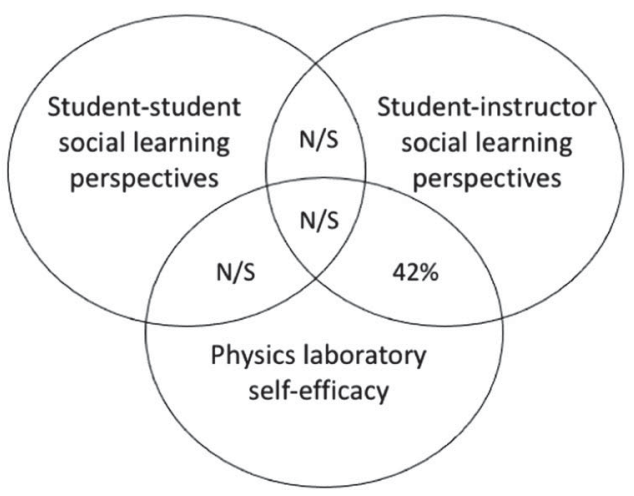

(c) Remote-isolated students

FIG. 2. Shared variance between factors for each group. Factors without significant shared variance are indicated by an "N/S".

were not significantly correlated with student-instructor social learning perspectives ( $p=0.717)$.

Remote-isolated students did not connect with their classmates, which may explain why only their interactions with their instructors related to their self-efficacy. They did not experience a social classroom environment.

\section{DISCUSSION AND IMPLICATIONS}

The results of the study showed notable differences in the social learning perspectives of in-person and remote students in physics laboratories. These differences may be explained though a social learning lens. The views of inperson students suggest they experienced a strong social learning environment shared with peers and instructors. Consequently, these students seemed to have more immediate access to sources of physics laboratory self-efficacy from one another and their instructors. Remote students on the whole lacked these same opportunities in terms of immediacy. Remote students who connected with one another seemed to form weaker communities of practice among one another with their instructors existing outside of the community structure. This may have limited their potential sources of physics laboratory self-efficacy. Isolated remote students operated outside a social learning environment making their instructors the only external source of physics laboratory self-efficacy. The results are discussed in terms of student-student social learning perspectives, student-instructor social learning perspectives, and physics laboratory self-efficacy.

\section{A. Student-student social learning perspectives}

In terms of student-student social learning perspectives, the in-person students reported more positive responses related to social integration, which was characterized by relying on others for support and motivation, a sense of social connectedness and belonging, and diminished isolation. The majority $(87 \%)$ of remote students surveyed were connecting with other students in their classes. In the absence of a formal or institutional learning community, remote connectors created their own or relied upon preexisting social networks or learning communities. Remote connectors were less socially integrated than in-person students, but more so than remote-isolated students. These results suggest that the physical proximity of in-person laboratories was related to social integration and selfefficacy. This is consistent with prior research establishing the classroom as the focal point of academic and social integration [41]. However, the remote networks did not 
fully replicate the social advantages of in-person communications. Even though most remote students were able to access a network of fellow students, those who did may not have established communities of practice that created affective value as well as their in-person counterparts. This may have been due to the lack of accountability in remote discussions, which often diminish the quality of interactions [73]. Remote discussions also lack the benefits of nonverbal cues such as body movements and vocal tone, which account for a large proportion of communication [74].

Some students remained isolated from their peers, completing their laboratory tasks on their own which may have been by choice or a result of circumstances. If by choice, their lack of engagement in social learning may have been due to a perceived lack of academic value [42], or they may have seen themselves as independent learners [75-77]. If students were not privy to informal communities, or were far removed from the campus community and lacked preexisting social connections, it might have been difficult to overcome isolation. Although participation may have depended upon the social inclinations of individual students, their tendencies may also have been specific to physics laboratory task completion. These tasks generally involved experimental processes, data collection and analysis, and preparing written reports. Since instruction was recorded and procedures were demonstrated, students could re-watch lectures and repeat experiments to improve data quality. The self-contained nature of the laboratory experience was intentionally designed, and outsiders may have felt this was sufficient for them to meet course standards.

\section{B. Student-instructor social learning perspectives}

In-person students responded more positively towards questions about their relationship with their instructors than their remote counterparts. This indicates that teaching assistants in the remote classes may not have provided students with the same level of feedback that in-person teaching assistants gave their students. Because in-person instructors are physically situated within the laboratory classroom among their students, they naturally become part of the laboratory community of practice structure. The teaching assistant acts as a facilitator for the community of practice, assuming a central role in the community $[42,46]$. This role and position within the community structure may create certain advantages for in-person instructors over their remote counterparts. In an in-person environment, students may receive immediate, specific, formative feedback from their teaching assistants as they are conducting experiments, feedback that could immediately impact students' thinking or practices [78]. Teaching assistants may validate a student's experimental setup, data they have collected, or data analysis. If a student experiences difficulty, they may rely upon the instructor's expertise in the community of practice and feel as though they can improve based on feedback [46].

The instructors' position within the community of practice also allows for feedback to flow from students to instructors [79]. When walking around the classroom and regularly interacting with students, instructors may build a rapport and foster positive interactions [80]. They may read nonverbal cues alerting them to when a student needs help without verbal initiation by a student [39]. They may build trust with their students [46], leading to a more connected classroom environment [80] and a stronger community of practice [42].

Because the communities of practice that formed within this remote laboratory class were informal, generated by the students without the instructor's recognition, the remote instructors were not a part of the community structure. As a result, remote instructors took on a different role than their in-person counterparts, potentially leading to a different relationship with their students. Remote teaching assistants may have been limited to serving as a resource to answer questions and provide feedback, not as a community facilitator, a much more valuable role [81]. Because of the asynchronous nature of the course, students were unlikely to get immediate, formative feedback while they were conducting their experiments. Most feedback they received was through emailing a teaching assistant, creating a time delay between the request and when feedback was given. While delaying feedback may encourage learners to engage in cognitive and metacognitive processes creating a higher sense of autonomy [78], delaying feedback may be detrimental to the learning of struggling or less motivated students [78], thus being less effective [82] and sometimes leading to frustration [78,79].

Remote students may require more accurate self-assessment to recognize when to initiate communication with their instructors [79]. This leaves much of the responsibility on the student to work autonomously and maintain their motivation [18]. The effort necessary to elicit feedback may be reduced if the student is more familiar with the instructor [83]. This makes the feedback "cost" higher for remote students. They must perceive the value of the feedback, for example, an increase in performance, as outweighing the associated cost [79]. This may factor in diminished studentinstructor social learning interactions; initiating communication with instructors may not provide enough value for students to do so.

The shared variance between student-student and student-instructor social learning perspectives may be explained by a relationship between each of these factors and a broader construct governing classroom connectedness and classroom environment. Previous literature has demonstrated the importance of simultaneously examining student-instructor and student-student interactions to understand classroom connectedness and environment $[80,84,85]$. Comparing the shared independent variance 
between student-student and student-instructor social learning perspectives done by in-person and remote-connector students shows that the in-person students may have experienced a more interconnected laboratory class than the remote students who are connected with one another through their own networks or communities. That is, the classroom social learning environment available to remote students did not match the social learning environment nurtured by an in-person class. Isolated remote students were effectively taking the class with limited instructor interaction and no peer interaction. Therefore, from a social learning perspective, their "classroom learning environment" was restricted.

\section{Physical laboratory self-efficacy}

In-person students responded more positively towards questions relating to their physics laboratory self-efficacy than remote students who connected with one another. Inperson students may have been more confident in their capabilities to complete the tasks and face the challenges posed by physics laboratory work than their remoteconnector counterparts. Though the effect size was small, it should be explored further. Students with higher selfefficacy have been shown to demonstrate more efficient self-monitoring $[49,86,87]$, self-regulation $[88,89]$ and time management [87]. These skills are helpful in a remote, autonomous environment making it all the more desirable to understand the self-efficacy of remote students $[88,89]$. Self-efficacy has also been shown to be a predictor of physics performance [90] as well as developing a physics identity [91,92], choosing a physics career [49,51,92], and physics retention [90,92]. If remote learning is to remain a viable avenue of access to physics laboratories for nontraditional students, it is important that academic and technological resources be made available to support students to overcome any challenges when taking a remote course [30].

Remote students who self-reported isolation from their peers showed no statistical difference in their physics laboratory self-efficacy between their remote-connecting or in-person counterparts. These students may have chosen to remain isolated because they were confident in their own capabilities and felt as though they did not need to work with other students. Students with stronger self-efficacy may be more capable of teaching themselves especially when they need to rely on their own initiative [49]. This may even be a contributing factor to selecting a remote course [76,77]. In the case of the physics laboratory, the course design may have contributed to students' selfefficacy. Clear expectations and explicit instructions, communicated through an online platform where procedures and some calculations were modeled may have provided all the interactions some students needed [18]. This may have fostered the confidence of students who were inherently independent.
For in-person students only, physics laboratory selfefficacy was positively correlated with student-student social learning perspectives (independent of studentinstructor social learning perspectives). Students may have influenced the self-efficacy of other students through vicarious learning experiences or through social persuasion. Vicarious learning may come about when a student is watching another student perform some task, influencing their decision to perform similar tasks $[49,93]$. In physics laboratories, this may come from watching another student collect data, perform calculations, or analyze data. The physical proximity of students in an in-person environment may facilitate this process.

The ways remote students interacted with one another in the present study, which is through self-generated social connections and communities of practice, did not seem to create vicarious learning opportunities that might facilitate self-efficacy. Social persuasion often comes about through verbal suggestions or words of encouragement from others [49]. While text communication utilized by remote students could replicate the verbal communication in-person students experienced, students must be motivated to participate in voluntary online discussions [94]. Remote students did not exhibit self-efficacy that may have been driven by interactions with peers.

The most significant correlation with physics laboratory self-efficacy for in-person students, and the only correlation for remote students, came from their instructors. An instructor's influence on a student's self-efficacy may come though several different sources. A student's mastery experiences, that is, direct evidence of one's success, are considered to be the most powerful source of self-efficacy [49]. Evidence of mastery in laboratories generally comes through feedback from instructors. While students can give one another feedback, peer feedback is seen as less valuable than instructor feedback because instructors ultimately control a student's final grade [95]. Feedback of success alone is not sufficient to increase self-efficacy. Self-efficacy may be generated though social validation of skill transmission or feedback [49]. In-person students likely experienced socially situated feedback inside their laboratory classroom, while remote students may not have experienced social validation.

Students may also experience vicarious learning from their instructors as a source of self-efficacy [49]. In the inperson laboratory, if a student was struggling with an experiment, the teaching assistant could walk over and, in the moment, demonstrate success for the student. This may have become a source of timely and supportive feedback, which may have nurtured self-regulated learning [79]. Vicarious learning may not have been a source of selfefficacy for remote students, consistent with prior research [96]. While they were given videos of an instructor conducting various parts of an experiment, students could not ask questions in the moment, making the communication effectively one way. While remote students could 
email questions to their teaching assistants, communication was typically asynchronous. Instructors and students were also not handling the same equipment in the same space, with students and instructors communicating with one another through text descriptions or pictures of problems.

\section{LIMITATIONS}

This study has several limitations. This research did not measure cognitive outcomes, which could provide a richer perspective of student outcomes related to course medium and social interaction. The sample was confined to a single higher education institution and may not be representative of the general population of college students. Sampling techniques in physics education research have been limited by nonrepresentative groups of participants in inferential analyses [97], which may be true in the present study since the sample was not representative of all students in undergraduate physics in the U.S.

The study was also limited by the collection of data at a single point in time. Students were surveyed once in the latter part of the fall semester, and the results did not reflect how students' views and behaviors may have changed during the course. Repeated measures would provide more nuanced insights into students' experiences over time. Instructors were not surveyed nor were they directly observed, so differences in instructional behaviors may have confounded survey results. However, most analyses of variance are limited by unobserved variables [98].

Nonequivalent group designs have an inherent selection bias issue [99]. Student enrollment in course type was not random but mostly self-selected. Some of this may have been offset by the COVID-19 pandemic; students who would normally take an in-person laboratory class instead chose to take a remote laboratory class because of safety concerns about in-person learning. Large-scale randomized studies would minimize threats to validity and reliability that exist when students self-select into groups. In addition, students may have experienced higher levels of emotional stress or anxiety due to the pandemic. This may have had a negative impact on self-efficacy [49].

In terms of social connections, student centrality within a social network was not measured, although this has been shown to have potential impact on the degree of positive outcomes [70]. Centrality could be measured by the frequency of communication with the network, which could be applied to both instructors and students.

\section{FUTURE RESEARCH}

The framework presented here as well as findings from the present study suggest several lines of inquiry in future research. Social network analysis (SNA) techniques may provide a useful lens and tools to study and analyze remote students' social connections. One could analyze a network's birth, cohesion, and evolution as well as how ideas flow through a network to understand how remote students connect with and share ideas with one another [100]. Temporal studies could be done analyzing the evolving nature of participation within a network over a single course, specifically examining how students move between peripheral and central roles within a community of practice. In a longitudinal study, identity development could be traced through an accumulation of participation in various communities of practice.

Exploring overlapping network structure between communities may offer insights into network and community formation, especially through preexisting social networks, and create opportunities to understand how ideas transfer between networks [101]. Qualitative data from student interviews may elicit nuances of how and why students connect (or fail to connect) to one another. This could also reveal specific practices transferring between overlapping communities of practice. SNA may be used to identify communities that otherwise might not be visible $[102,103]$. Social graphing techniques could provide insights into remote students' positions within a class network, making it easier to identify lurkers or other students on the periphery $[102,104]$. Student placement and roles within a network could be studied to understand the roles of centrality and density within a remote learning network. SNA could also provide insights into the impacts of different pedagogical strategies [105].

In this study, physics laboratory self-efficacy was linked to social learning perspectives. Conceptual understanding, inquiry or practical skills, and other learning outcomes have been previously studied in in-person vs remote settings [34]; these outcomes could be tested against factors relating to social learning perspectives to understand their relationship to socialization (especially in a remote laboratory environment).

\section{CONCLUSIONS}

Researchers comparing in-person labs to remote labs have often examined whether student outcomes in a remote laboratory were equivalent to in-person laboratory outcomes. Most work has focused on cognitive outcomes such as conceptual understanding or performance $[25,34]$. This is a concern for researchers since it is preferable that students' performance is not hindered by their academic environment. From the social learning perspective, students' interactions with peers and instructors are a necessary, central, and natural part of the learning process. In-person classes facilitate these interactions by virtue of working in the same physical space. Remote classes do not have this inherent structure, and social interaction requires more intentional processes. As demonstrated in the present study, even when students are connecting socially or forming their own communities of practice, remote students may have inequitable learning experiences compared to in-person learners. Designing and implementing a remote course through a 
social learning lens requires careful consideration of how affective and cognitive outcomes relate to the ways students interact in the remote environment.

If the classroom is to be "the crossroads where the social and the academic meet" [41] (p. 599), what should the remote classroom look like? Students should still engage with others through their own social networks and the communities they choose to form. However, remote students may benefit from a dedicated, virtual space where students and instructors can meet and interact. Such a shared space could serve to facilitate sources of laboratory self-efficacy which could then lead to other benefits including building a shared identity and improving performance. Remote students often need to be self-motivated to seek out or participate in discussions with their peers or to elicit feedback from their instructors, even in an established community of practice.

Instructors in remote courses may serve not only as facilitators of a learning community of practice but also as a source of self-efficacy, which can then positively contribute to a student's motivation [106]. One way instructors may increase motivation is by communicating the value of engagement. Feedback, particularly formative feedback, could be embedded within the laboratories themselves relieving some of the responsibility from the instructors turning the autonomous nature of remote work into an advantage. Videos of students engaging in a dialog with a teaching assistant about a laboratory as part of the "lab manual" instead of the more traditional didactic video or text method can be a source of autonomous feedback. It also creates an opportunity for vicarious learning which can serve as a positive source of physics laboratory selfefficacy [96,107]. Instructors may need more formalized training beyond what is typically provided; those unfamiliar with remote learning may incorrectly apply in-person practices in a remote setting. All of this requires time and professional development, which was severely constrained when transitioning during the COVID-19 pandemic [11], and may still be an impediment in future semesters [108].

If physics is to be truly accessible for all, a thoughtfully designed remote physics laboratory experience with social learning practices built into the course design is a worthwhile investment in time and resources to promote equitable physics laboratory experiences.

\section{ACKNOWLEDGMENTS}

The authors would like to thank Thomas Hemmick, Rich Lefferts, and the anonymous reviewers for their valuable commentary. D. R. would like to thank Natasha Holmes for her insights during the preliminary stages of this study as well as her help with the factor analysis, and MacKenzie Stetzer for his insights during the later stage of this study. This research was supported by the State University of New York (SUNY) Excels Project and the Stony Brook University S-BOLD Initiative. The study was approved by the Stony Brook University Institutional Review Board (No. 1316679).
[1] J. Kozminski, H. J. Lewandowski, N. Beverly, S. Lindaas, D. Deardorff, A. Reagan, R. Dietz, R. Tagg, M. EblenZayas, J. Williams, R. Hobbs, and B. M. Zwickl, AAPT committee on laboratories, AAPT Recommendations for the Undergraduate Physics Laboratory Curriculum (AAPT, College Park, MD, 2014).

[2] A. Hofstein and V. N. Lunetta, The laboratory in science education: Foundations for the twenty-first century, Sci. Educ. 88, 28 (2004).

[3] R. P. Feynman, R. B. Leighton, and M. Sands, The Feynman Lectures on Physics: Mainly Mechanics, Radiation, and Heat (Basic Books, New York, 1963), Vol. 1.

[4] N. Holmes and H. Lewandowski, Investigating the landscape of physics laboratory instruction across North America, Phys. Rev. Phys. Educ. Res. 16, 020162 (2020).

[5] J. J. Park, N. H. Choe, D. L. Schallert, and A. K. Forbis, The chemical engineering research laboratory as context for graduate students' training: The role of lab structure and cultural climate in collaborative work, Learn. Culture Soc. Interaction 13, 113 (2017).
[6] A. Roychoudhury and W.-M. Roth, Interactions in an open-inquiry physics laboratory, Int. J. Sci. Educ. 18, 423 (1996).

[7] C. Hodges, S. Moore, B. Lockee, T. Trust, and A. Bond, The difference between emergency remote teaching and online learning, Educause Rev. 27, 1 (2020), https://er .educause.edu/articles/2020/3/the-difference-betweenemergency-remote-teaching-and-online-learning.

[8] B. Wilcox and M. Vignal, Understanding the student experience with emergency remote teaching, in Proceedings of the 2020 Physics Education Research Conference, virtual conference (AIP, New York, 2020).

[9] B. Wilcox and M. Vignal, Recommendations for emergency remote teaching based on the student experience, Phys. Teach. 58, 374 (2020).

[10] L. F. Z. Rivera and M. M. Larrondo-Petrie, Models of collaborative remote laboratories and integration with learning environments, Int. J. Online Eng. 12, 14 (2016).

[11] M. F. Fox, A. Werth, J. R. Hoehn, and H. Lewandowski, Teaching labs during a pandemic: Lessons from spring 2020 and an outlook for the future, arXiv:2007.01271. 
[12] B. Latour and S. Woolgar, Laboratory Life: The Construction of Scientific Facts (Princeton University Press, Princeton, NJ, 2013).

[13] S. Wuchty, B.F. Jones, and B. Uzzi, The increasing dominance of teams in production of knowledge, Science 316, 1036 (2007).

[14] R. Dou and J. P. Zwolak, Practitioner's guide to social network analysis: Examining physics anxiety in an activelearning setting, Phys. Rev. Phys. Educ. Res. 15, 020105 (2019).

[15] H. S. Fencl and K. R. Scheel, Pedagogical approaches, contextual variables, and the development of student selfefficacy in undergraduate physics courses, AIP Conf. Proc. 720, 173 (2004).

[16] S. Dawson, A study of the relationship between student social networks and sense of community, Educ. Technol. Soc. 11, 224 (2008), https://eric.ed.gov/?id=EJ814127.

[17] E. Wenger, B. Trayner, and M. De Laat, Promoting and Assessing Value Creation in Communities and Networks: A Conceptual Framework, Rapport 18 (Ruud de Moor Centrum, Open Universiteit Nederland, 2011).

[18] M. Moore, Three types of interaction, Am. J. Distance Educ. 3, 1 (1989).

[19] J. Lopes, C. Viegas, and J. Cravino, Improving the learning of physics and development of competences in engineering students, Int. J. Eng. Educ. 26, 612 (2010), https://www.researchgate.net/publication/286984317_ Improving_the_Learning_of_Physics_and_Development_ of_Competences_in_Engineering_Students.

[20] L. S. Vygotsky, Mind in Society: The Development of Higher Psychological Processes (Harvard University Press, Cambridge, MA, 1980).

[21] S. Olitsky, Promoting student engagement in science: Interaction rituals and the pursuit of a community of practice, J. Res. Sci. Teach. 44, 33 (2007).

[22] H.-H. Pai, D. A. Sears, and Y. Maeda, Effects of smallgroup learning on transfer: A meta-analysis, Educ. Psychol. Rev. 27, 79 (2015).

[23] M. A. Pease and D. Kuhn, Experimental analysis of the effective components of problem-based learning, Sci. Educ. 95, 57 (2011).

[24] J. Wei, D. F. Treagust, M. Mocerino, A. D. Lucey, M. G. Zadnik, and E. D. Lindsay, Understanding interactions in face-to-face and remote undergraduate science laboratories: A literature review, Discip. Interdiscip. Sci. Educ. Res. 1, 1 (2019).

[25] J. Ma and J. V. Nickerson, Hands-on, simulated, and remote laboratories: A comparative literature review, ACM Comput. Surv. (CSUR) 38, 7 (2006).

[26] J. Good, K. Colthorpe, K. Zimbardi, and G. Kafer, The roles of mentoring and motivation in student teaching assistant interactions and in improving experience in firstyear biology laboratory classes, J. Coll. Sci. Teach. 044, 88 (2015).

[27] E. Lindsay, S. Naidu, and M. Good, A different kind of difference: Theoretical implications of using technology to overcome separation in remote laboratories, Int. J. Eng. Educ. 23, 772 (2007).
[28] M. Cooper and J. M. Ferreira, Remote laboratories extending access to science and engineering curricular, IEEE Trans. Learn. Technol. 2, 342 (2009).

[29] C. Colwell, E. Scanlon, and M. Cooper, Using remote laboratories to extend access to science and engineering, Comput. Educ. 38, 65 (2002).

[30] P.-S. D. Chen, A. D. Lambert, and K. R. Guidry, Engaging online learners: The impact of web-based learning technology on college student engagement, Comput. Educ. 54, 1222 (2010).

[31] E. Scanlon, J. Schreffler, W. James, E. Vasquez, and J. J. Chini, Postsecondary physics curricula and universal design for learning: Planning for diverse learners, Phys. Rev. Phys. Educ. Res. 14, 020101 (2018).

[32] F. Al-Shamali and M. Connors, Low-cost physics home laboratory, in Accessible Elements: Teaching Science Online and at a Distance, edited by D. K. Kennepohl and L. Shaw ( Athabasca University Press, Edmonton, Alberta, 2010), pp. 131-145.

[33] C.-H. Wang, D. M. Shannon, and M. E. Ross, Students' characteristics, self-regulated learning, technology selfefficacy, and course outcomes in online learning, Distance Educ. 34, 302 (2013).

[34] J. R. Brinson, Learning outcome achievement in nontraditional (virtual and remote) versus traditional (handson) laboratories: A review of the empirical research, Comput. Educ. 87, 218 (2015).

[35] T. De Jong, M. C. Linn, and Z. C. Zacharia, Physical and virtual laboratories in science and engineering education, Science 340, 305 (2013).

[36] A. Bandura, Self-efficacy: Toward a unifying theory of behavioral change, Psychol. Rev. 84, 191 (1977).

[37] H. Cho, G. Gay, B. Davidson, and A. Ingraffea, Social networks, communication styles, and learning performance in a CSCL community, Comput. Educ. 49, 309 (2007).

[38] M. LaPadula, A comprehensive look at online student support services for distance learners, Am. J. Distance Educ. 17, 119 (2003).

[39] B. G. Davis, Tools for Teaching (John Wiley \& Sons, New York, 2009).

[40] I. Leki, Undergraduates in a Second Language: Challenges and Complexities of Academic Literacy Development (Routledge, London, 2017).

[41] V. Tinto, Classrooms as communities: Exploring the educational character of student persistence, J. Higher Educ. 68, 599 (1997).

[42] E. Wenger, R. A. McDermott, and W. Snyder, Cultivating Communities of Practice: A guide to Managing Knowledge (Harvard Business School Press, Boston, MA, 2002).

[43] P. W. Irving and E. C. Sayre, Conditions for building a community of practice in an advanced physics laboratory, Phys. Rev. ST Phys. Educ. Res. 10, 010109 (2014).

[44] J. Lave and E. Wenger, Situated Learning: Legitimate Peripheral Participation (Cambridge University Press, Cambridge, MA, 1991).

[45] E. Wenger, Communities of Practice: Learning, Meaning, and Identity ( Cambridge University Press, Cambridge, MA, 1998). 
[46] P. W. Irving, D. McPadden, and M. D. Caballero, Communities of practice as a curriculum design theory in an introductory physics class for engineers, Phys. Rev. Phys. Educ. Res. 16, 020143 (2020).

[47] A. P. Rovai, Sense of community, perceived cognitive learning, and persistence in asynchronous learning networks, Internet High. Educ. 5, 319 (2002).

[48] M. Goos, P. Galbraith, and P. Renshaw, Socially mediated metacognition: Creating collaborative zones of proximal development in small group problem solving, Educ. Stud. Math. 49, 193 (2002).

[49] A. Bandura, Self-efficacy: The Exercise of Control (Macmillan, New York, 1997).

[50] J. Wang and Z. Hazari, Promoting high school students' physics identity through explicit and implicit recognition, Phys. Rev. Phys. Educ. Res. 14, 020111 (2018).

[51] N. E. Betz and G. Hackett, Applications of self-efficacy theory to understanding career choice behavior, J. Soc. Clin. Psychol. 4, 279 (1986).

[52] D. J. Rosen and A. M. Kelly, Epistemology, socialization, help seeking, and gender-based views in in-person and online, hands-on undergraduate physics laboratories, Phys. Rev. Phys. Educ. Res. 16, 020116 (2020).

[53] C. S. Reichardt, Quasi-experimental design, in The SAGE Handbook of Quantitative Methods in Psychology, edited by R. E. Millsap and A. Maydeu-Olivares ( Sage, London, UK, 2009), Vol. 46, pp. 46-71.

[54] iOLab Macmillan Learning, http://www.iolab.science/ documents/iOLab_Description_onepage.pdf, accessed 3-30-2021.

[55] A. Almaatouq, M. Alsobay, M. Yin, and D. J. Watts, Task complexity moderates group synergy, Proc. Natl. Acad. Sci. U.S.A. 118, 1 (2021).

[56] B. J. Fraser, G. J. Giddings, and C. J. McRobbie, Evolution and validation of a personal form of an instrument for assessing science laboratory classroom environments, J. Res. Sci. Teach. 32, 399 (1995).

[57] A. Mason and C. Singh, Surveying graduate students' attitudes and approaches to problem solving, Phys. Rev. ST Phys. Educ. Res. 6, 020124 (2010).

[58] A. P. Rovai, Development of an instrument to measure classroom community, Internet High. Educ. 5, 197 (2002).

[59] E. A. Barnett, Validation experiences and persistence among community college students, Rev. High. Educ. 34, 193 (2010).

[60] J. Dalgety, R. K. Coll, and A. Jones, Development of chemistry attitudes and experiences questionnaire (CAEQ), J. Res. Sci. Teach. 40, 649 (2003).

[61] J. A. Baldwin, D. Ebert-May, and D. J. Burns, The development of a college biology self-efficacy instrument for nonmajors, Sci. Educ. 83, 397 (1999).

[62] L. E. Kost-Smith, Ph.D. thesis, University of Colorado at Boulder, 2011.

[63] K. Miller, J. Schell, A. Ho, B. Lukoff, and E. Mazur, Response switching and self-efficacy in peer instruction classrooms, Phys. Rev. ST Phys. Educ. Res. 11, 010104 (2015).

[64] Z. Y. Kalender, E. Marshman, C. D. Schunn, T. J. NokesMalach, and C. Singh, Damage caused by women's lower self-efficacy on physics learning, Phys. Rev. Phys. Educ. Res. 16, 010118 (2020).

[65] P. G. Curran, Methods for the detection of carelessly invalid responses in survey data, J. Exp. Soc. Psychol. 66, 4 (2016).

[66] H. F. Kaiser, An index of factorial simplicity, Psychometrika 39, 31 (1974).

[67] E. A. Williams, J. P. Zwolak, R. Dou, and E. Brewe, Linking engagement and performance: The social network analysis perspective, Phys. Rev. Phys. Educ. Res. 15, 020150 (2019).

[68] T. E. Rizzuto, J. LeDoux, and J. P. Hatala, It's not just what you know, it's who you know: Testing a model of the relative importance of social networks to academic performance, Soc. Psychol. Educ. 12, 175 (2009).

[69] J. Bruun and E. Brewe, Talking and learning physics: Predicting future grades from network measures and Force Concept Inventory pretest scores, Phys. Rev. ST Phys. Educ. Res. 9, 020109 (2013).

[70] R. Dou, E. Brewe, J. P. Zwolak, G. Potvin, E. A. Williams, and L. H. Kramer, Beyond performance metrics: Examining a decrease in students' physics selfefficacy through a social networks lens, Phys. Rev. Phys. Educ. Res. 12, 020124 (2016).

[71] J. Cohen, A power primer, Psychol. Bull. 112, 155 (1992).

[72] K. Moder, Alternatives to f-test in one way ANOVA in case of heterogeneity of variances (a simulation study), Psychol. Test Assess. Model. 52, 343 (2010), https:// www.psychologie-aktuell.com/fileadmin/download/ ptam/4-2010_20101218/01_Moder.pdf.

[73] H. Smith, Assessing student contributions to online discussion boards, Practitioner Res. Higher Educ. 2, 22 (2008), https://files.eric.ed.gov/fulltext/EJ1130596.pdf.

[74] F. B. Mandal, Nonverbal communication in humans, J. Human Behav. Social Environ. 24, 417 (2014).

[75] T. Anderson, Getting the mix right again: An updated and theoretical rationale for interaction, Int. Rev. Res. Open Distrib. Learn. 4, 1 (2003).

[76] N.Z. Zacharis, The effect of learning style on preference for web-based courses and learning outcomes, Br. J. Educ. Technol. 42, 790 (2011).

[77] S. R. Terrell and L. Dringus, An investigation of the effect of learning style on student success in an online learning environment, J. Educ. Technol. Syst. 28, 231 (2000).

[78] V. J. Shute, Focus on formative feedback, Rev. Educ. Res. 78, 153 (2008).

[79] J. Hattie and H. Timperley, The power of feedback, Rev. Educ. Res. 77, 81 (2007).

[80] B. N. Frisby and M. M. Martin, Instructor-student and student-student rapport in the classroom, Commun. Educ. 59, 146 (2010).

[81] K. D. Squire and C. B. Johnson, Supporting distributed communities of practice with interactive television, Educ. Technol. Res. Dev. 48, 23 (2000).

[82] J. A. Kulik and C.-L. C. Kulik, Timing of feedback and verbal learning, Rev. Educ. Res. 58, 79 (1988).

[83] S. J. Ashford and L. L. Cummings, Feedback as an individual resource: Personal strategies of creating in- 
formation, Organ. Behav. Hum. Decis. Process. 32, 370 (1983).

[84] D. I. Johnson, Connected classroom climate: A validity study, Commun. Res. Reports 26, 146 (2009).

[85] R. J. Sidelinger and M. Booth-Butterfield, Co-constructing student involvement: An examination of teacher confirmation and student-to-student connectedness in the college classroom, Commun. Educ. 59, 165 (2010).

[86] A. Bandura, Social cognitive theory of self-regulation, Organ. Behav. Hum. Decis. Process. 50, 248 (1991).

[87] B. J. Zimmerman, Self-efficacy: An essential motive to learn, Contemp. Educ. Psychol. 25, 82 (2000).

[88] R. L. Bradley, B. L. Browne, and H. M. Kelley, Examining the influence of self-efficacy and self-regulation in online learning, Coll. Stud. J. 51, 518 (2017), https://eric .ed.gov/?id=EJ1162424.

[89] M.-H. Cho and D. Shen, Self-regulation in online learning, Distance Educ. 34, 290 (2013).

[90] V. Sawtelle, E. Brewe, and L. H. Kramer, Exploring the relationship between self-efficacy and retention in introductory physics, J. Res. Sci. Teach. 49, 1096 (2012).

[91] Z. Y. Kalender, E. Marshman, C. D. Schunn, T. J. NokesMalach, and C. Singh, Gendered patterns in the construction of physics identity from motivational factors, Phys. Rev. Phys. Educ. Res. 15, 020119 (2019).

[92] Z. Hazari, G. Sonnert, P. M. Sadler, and M.-C. Shanahan, Connecting high school physics experiences, outcome expectations, physics identity, and physics career choice: A gender study, J. Res. Sci. Teach. 47, 978 (2010).

[93] D. H. Schunk, Peer models and children's behavioral change, Rev. Educ. Res. 57, 149 (1987).

[94] K. Xie, T. K. Debacker, and C. Ferguson, Extending the traditional classroom through online discussion: The role of student motivation, J. Educ. Comput. Res. 34, 67 (2006).

[95] K. J. Rodgers, A. K. Horvath, H. Jung, A. S. Fry, H. Diefes-Dux, and M. E. Cardella, Students' perceptions of and responses to teaching assistant and peer feedback, Interdiscip. J. Problem-based Learn. 9, 2 (2015).
[96] D. A. Muller, M. D. Sharma, J. Eklund, and P. Reimann, Conceptual change through vicarious learning in an authentic physics setting, Instr. Sci. 35, 519 (2007).

[97] S. Kanim and X.C. Cid, Demographics of physics education research, Phys. Rev. Phys. Educ. Res. 16, 020106 (2020).

[98] A. Field, Discovering Statistics Using IBM SPSS Statistics (Sage, Los Angeles, CA, 2013).

[99] C.S. Reichardt, Nonequivalent group design, Wiley StatsRef: Statistics Reference Online, (John Wiley \& Sons, Inc, Hoboken, NJ, 2014).

[100] A. Marin and B. Wellman, Social network analysis: An introduction, in The SAGE Handbook of Social Network Analysis, edited by J. Scott and P. J. Carrington (SAGE Publications, Los Angeles, CA, 2011), pp. 11-25.

[101] G. Palla, I. Derényi, I. Farkas, and T. Vicsek, Uncovering the overlapping community structure of complex networks in nature and society, Nature (London) 435, 814 (2005).

[102] S. Fortunato, Community detection in graphs, Phys. Rep. 486, 75 (2010).

[103] A. Lancichinetti and S. Fortunato, Community detection algorithms: A comparative analysis, Phys. Rev. E 80, 056117 (2009).

[104] J. S. Saltz, S. R. Hiltz, and M. Turoff, Student social graphs: Visualizing a student's online social network, in Proceedings of the 2004 ACM Conference on Computer Supported Cooperative Work (Association for Computer Machinery, New York, NY, 2004), pp. 596-599.

[105] D. Z. Grunspan, B. L. Wiggins, and S. M. Goodreau, Understanding classrooms through social network analysis: A primer for social network analysis in education research, CBE Life Sci. Educ. 13, 167 (2014).

[106] A. P. Rovai, Facilitating online discussions effectively, Internet High. Educ. 10, 77 (2007).

[107] M. T. Chi, M. Roy, and R. G. Hausmann, Observing tutorial dialogues collaboratively: Insights about human tutoring effectiveness from vicarious learning, Cogn. Sci. 32, 301 (2008).

[108] M. Dancy and C. Henderson, Pedagogical practices and instructional change of physics faculty, Am. J. Phys. 78, 1056 (2010). 